\title{
Brake Noise Reduction Method Based on Monte Carlo Sampling and Particle Swarm Optimization
}

\author{
Yihong Gu $\mathbb{D},,^{1,2}$ Yucheng Liu $\mathbb{D}^{3,4}$ and Congda Lu $\left.{ }^{1}\right)^{1}$ \\ ${ }^{1}$ College of Mechanical Engineering, Zhejiang University of Technology, Hangzhou 310014, China \\ ${ }^{2}$ Quzhou College of Technology, Quzhou 324000, China \\ ${ }^{3}$ Zhejiang Wanda Steering Gear Co., Ltd., Hangzhou 311258, China \\ ${ }^{4}$ College of Energy Engineering, Zhejiang University, Hangzhou 310023, China \\ Correspondence should be addressed to Congda Lu; lcd@zjut.edu.cn
}

Received 3 July 2020; Revised 7 March 2021; Accepted 17 March 2021; Published 30 March 2021

Academic Editor: Arcanjo Lenzi

Copyright (C) 2021 Yihong Gu et al. This is an open access article distributed under the Creative Commons Attribution License, which permits unrestricted use, distribution, and reproduction in any medium, provided the original work is properly cited.

\begin{abstract}
Brake noise is one of the principal components of vehicle noise and is also one of the most critical measures of vehicle quality. During the braking process, the occurrence of brake noise has a significant relationship with the working conditions of the brake system. In the present study, dynamometer test data and the finite element method (FEM) were used to analyze the direct and indirect effects of variations in the working parameters on the brake noise, and a brake noise reduction method was developed. With this method, Monte Carlo sampling was used to consider variations in the parameters of the brake lining during the braking procedure, and the particle swarm optimization method was used to calculate the optimal parameter combination for the brake lining. A dynamometer test was carried out to validate the effect of optimization on brake noise mitigation.
\end{abstract}

\section{Introduction}

Brake noise, especially high-frequency brake squeal, is one of the principal components of vehicle noise. It may cause noise pollution and directly affect the ride comfort of a vehicle [1]. As the number of automobiles increases, the environmental impact caused by brake noise becomes more serious. Disc brakes are the most common type of brake system and are widely used in passenger cars and light commercial vehicles. Because reducing the brake noise is an obvious way to improve the riding comfort of a vehicle, the noise control of disc brakes has become a focus of vehicle noise, vibration, and harshness (NVH) engineering. It is also an important part of the development process for the brake system or entire vehicle [2].

The dynamometer test and finite element method (FEM) are important means of studying brake noise. The former is used to evaluate the brake noise under real braking conditions, and the latter is widely used to consider the geometry characteristics and material properties of parts for the development of a brake system. The frequency domain complex-eigenvalue method is a common analytical approach using the FEM [3]. It was introduced in the 1980s and is currently one of the most important means of predicting brake noise and guiding brake design in engineering [4]. The FEM has been used in many studies to examine the effects of geometric characteristics or material properties of a brake lining on the brake noise. Studies on geometric characteristics have been focused on the geometry, structure, wear, or slot of the brake lining [5-7], and studies on material properties have concentrated on the elastic modulus, damping, frictional coefficient, or surface characteristics of the brake friction material [8-11].

Existing research has shown that, in addition to the shape and material parameters, the working conditions also have a significant impact on the occurrence of brake noise [12]. Because of the strong randomness during the braking process, research on the influence of working conditions on noise has been very limited. Fazio et al. [13] and Tison et al. [14] investigated the influence of working parameters on the contact interfaces of the brake system. Soobbarayen et al. [15] studied the influence of loading conditions on the vibrational and acoustic responses of the disc brake system. Lee et al. [16] studied the effect of humidity on the friction coefficient of a 
brake material. Some studies introduced uncertainty of the working parameters into a numerical model of the brake system to study the effect of the brake noise [17-19].

In the present study, dynamometer test data and the FEM were used to analyze the direct and indirect effects of variations in the working parameters on the brake noise and examine the main cause for the occurrence of brake noise with changes in the working parameters. A brake noise reduction method based on Monte Carlo sampling and particle swarm optimization (PSO) was developed that is based on the randomness of the working parameters during the braking process. An optimization scheme for the brake lining structure and material parameters was developed, and a dynamometer test was carried out to test the effectiveness of the optimization method.

\section{Analysis of Brake Noise with the FEM}

For a general vibrating system, the vibration can be expressed as

$$
M \ddot{x}+C \dot{x}+K x=F,
$$

where $M, C$, and $K$ are the mass, damping, and stiffness matrices, respectively, of the system; $x$ is the displacement vector; and $F$ is the excitation force of the system. For a brake system, the friction force is introduced as the excitation force during the braking process. The force vector of $F$ can be obtained after simplification:

$$
F=\mu K_{f} x,
$$

where $\mu$ is the friction coefficient between the brake lining and disc and $K_{f}$ is the friction stiffness matrix. By combining equations (1) and (2), a homogeneous equation can be obtained [20]:

$$
M \ddot{x}+C \dot{x}+\left(K-\mu K_{f}\right) x=0,
$$

Equation (3) shows that, because of the existence of the friction force, the system stiffness is coupled and the stiffness matrix is asymmetric, which in turn results in asymmetry of the characteristic matrix. Therefore, the eigenvalues of the characteristic matrix may be complex under certain conditions. For an underdamped system, the eigenvalues always occur in complex conjugate pairs. The characteristic equation is given by

$$
\begin{array}{r}
\operatorname{det}\left(\lambda^{2} M+\lambda C+K-\mu K_{f}\right)=0, \\
\lambda_{i 1,2}=\sigma_{i} \pm j \omega_{i},
\end{array}
$$

where $\lambda_{i}$ is the eigenvalue of the $i^{\text {th }}$ mode of the system, $\sigma_{i}$ is the real part of the eigenvalue and represents the attenuation coefficient of the corresponding mode, and $\omega_{i}$ is the imaginary part of the eigenvalue and represents the natural angular frequency of the corresponding mode. The damping ratio of the corresponding mode is

$$
\zeta_{i}=-\frac{\sigma_{i}}{\omega_{i}}
$$

Therefore, the stability of a system can be determined according to whether $\sigma$ is positive or negative. If $\sigma_{i}<0$, the damping ratio is positive, the vibration of the system will decay over time, and the system is stable under this condition. If $\sigma_{i}>0$, the damping ratio is negative, and the vibration of the system will not decay. This means that the corresponding mode is unstable. Under this condition, the absolute value of the damping ratio reflects the instability of system. A higher value increases the possibility of brake noise occurring [21].

When the brake pedal is stepped down, the piston and the caliper in the brake assembly were driven by the rising brake fluid pressure and pushed the brake pads to move towards the rotating brake disk. In the present study, the brake system of a passenger car's front axle was chosen as the subject of research. Hypermesh 13.0 was used to mesh the model after simplification, while different parts were set to element sizes of 3-5 mm [22]. The model was meshed into 151942 elements of the C3D10M (10-node modified tetrahedron element with hourglass control). Figure 1 shows the original model and FEM. Table 1 presents the material properties of each part of the brake system.

Table 2 lists all interactions defined in the finite element model of brake system. In this study, the tie and surf-surf contact interactions were used to simulate the contact relationship between the various surfaces. Brake noise is affected by the friction coefficient between the disk and lining; the nominal friction coefficient provided by the frictionmaterial manufacturer (and corrected through dynamometer tests) was used in the present analysis.

The bracket of the brake system was fixed on the knuckle by its own threaded hole, so the inner surfaces of both threaded holes were constrained in the FEM. On the other hand, the disc was clamped by the wheel hub and knuckle through screws, so the inner and outer surfaces of the convex plate on the disc were constrained. A prestressed modal was built to simulate the brake process. At first, a load of $3 \mathrm{MPa}$ was applied to the end face of the piston to simulate the brake pressure. And in the next step, a rotational speed of the disc was defined with an equivalent linear velocity of $3 \mathrm{~km} / \mathrm{h}$ by editing the keywords of MOTION ROTATION in the inp file for Abaqus analysis.

The brake system model after preprocessing was submitted to Abaqus 6.13-4 for complex modal analysis by using standard solver, and the Lanczos method was used to extract the eigenvalues of the system. Considering that the model involves contact and friction, NLGEOM was turned on for geometric nonlinearity, and unsymmetric matrix storage and solution scheme was used for the complex-eigenvalue extraction procedure [23].

Based on engineering experience, modes in the analysis results with a damping ratio of less than $-0.6 \times 10^{-2}$ were treated as noise and are given in Table 2. In addition, a dynamometer test based on SAE J2521 was carried out to verify the accuracy of the FEM. Figure 2 shows the frequency distribution and sound pressure level data. In the dynamometer test, brake squeal occurred at frequencies of 7800 , 8800 , and $11000 \mathrm{~Hz}$. In the frequency band of $3000-4400 \mathrm{~Hz}$, brake noise also occurred, but the frequency of the noise was fragmented. This was related to property changes of the brake system caused by low temperatures in 


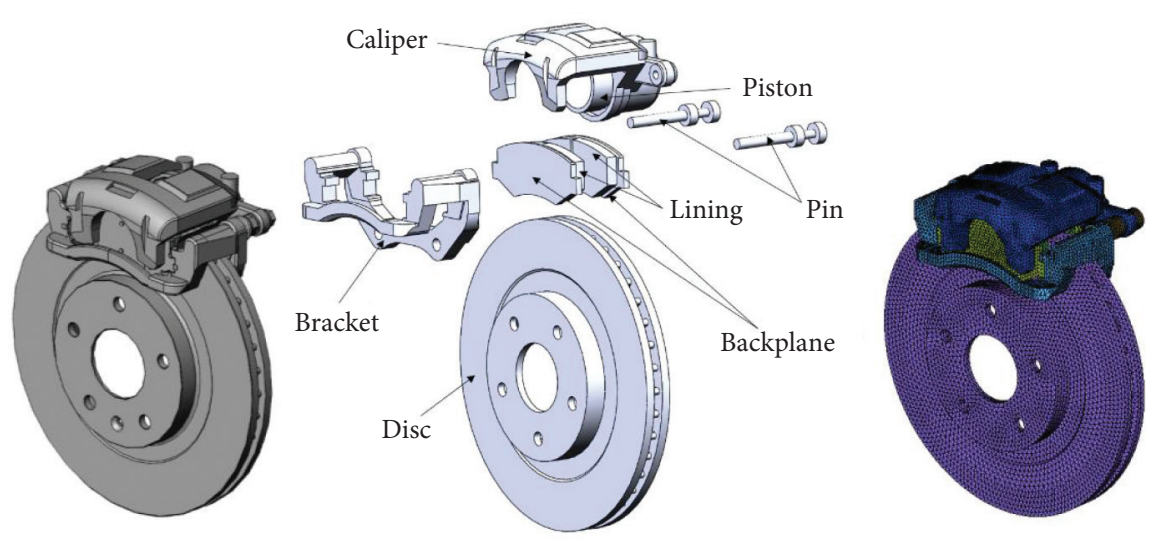

FIgURE 1: Original model and FEM of the brake system.

TABLE 1: Material properties of parts of the brake system.

\begin{tabular}{lccccc}
\hline Part & Material & Density $\left(10^{3} \mathrm{~kg} / \mathrm{m}^{3}\right)$ & Elastic modulus $(\mathrm{MPa})$ & Poisson's ratio & Element size $(\mathrm{mm})$ \\
\hline Disc & HT250 & 7.15 & 120000 & 0.26 & 5.0 \\
Caliper & QT450 & 6.86 & 173500 & 0.3 & 3.5 \\
Bracket & QT450 & 6.86 & 173500 & 0.3 & 3.5 \\
Piston & 35\# & 7.85 & 212000 & 0.31 & 3.0 \\
Pin & Q345 & 7.85 & 206000 & 0.28 & 3.0 \\
Backplane & Q345 & 7.85 & 206000 & 0.36 & 3.0 \\
Lining & NAO & 1.61 & 709 & 3.0 \\
\hline
\end{tabular}

TABLE 2: Interactions in the brake system finite element model.

\begin{tabular}{|c|c|c|c|}
\hline Contact pair & Interaction type & Number of contact pairs in the model & Friction coefficient \\
\hline Backplate bracket & Surf-surf contact & 4 & 0.16 \\
\hline Backplate piston & Surf-surf contact & 1 & 0.10 \\
\hline Backplate caliper & Surf-surf contact & 1 & 0.16 \\
\hline Bracket pin & Surf-surf contact & 2 & 0.05 \\
\hline Piston caliper & Surf-surf contact & 1 & 0.16 \\
\hline Lining disc & Surf-surf contact & 2 & 0.48 \\
\hline Lining backplate & Tie & 2 & - \\
\hline Pin caliper & Tie & 2 & - \\
\hline
\end{tabular}

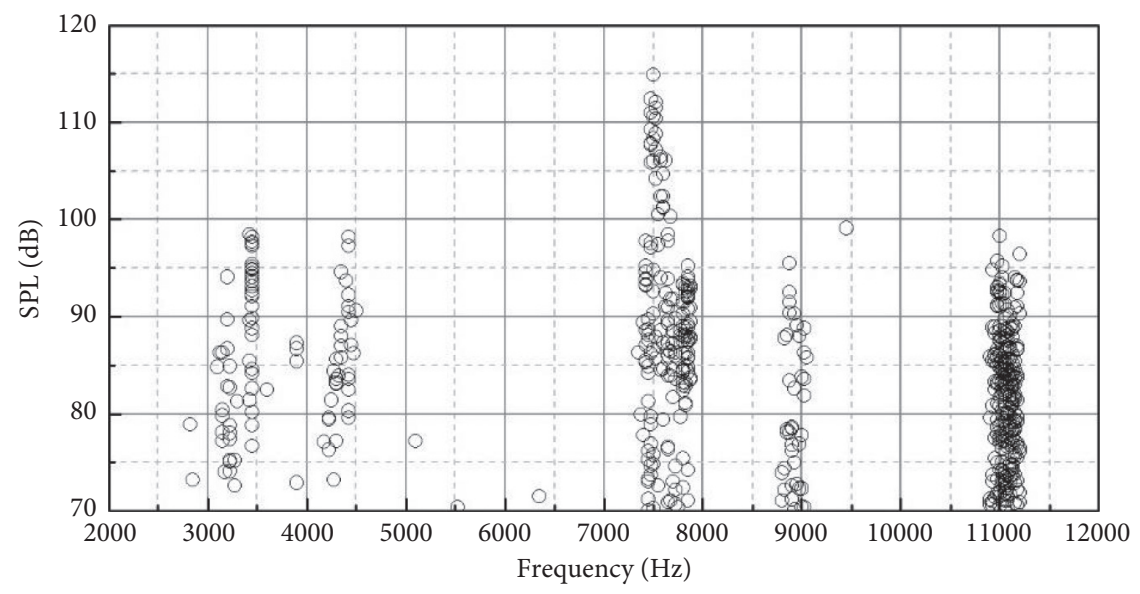

FIgURE 2: Noise distribution in the dynamometer test. 
the cold section of the test. When compared with the data in Table 3, most of the noisy modes were in agreement with the test results regarding the frequency distribution, and the 104 th mode had a frequency error of less than $4 \%$. Thus, the FEM was concluded to be sufficiently accurate to satisfy the demands for analysis.

\section{Influence of Working Parameters on Brake Noise}

3.1. Analysis of Dynamometer Test Results. To investigate the brake noise for different driving states of a vehicle, various combinations of working parameters including the brake pressure, brake speed, and initial rotor temperature were considered using the dynamometer test procedure of SAE J2521. The SAE J2521 disc and drum brake dynamometer squeal noise test procedure is intended to establish a common method to perform a series of screening test sequences that identify the propensity of a brake assembly to generate squeal noise under a variety of test conditions. It uses two main modes: (a) drag mode at low speed with a pressure application profile meant to induce instability and squeal noise and (b) deceleration braking at moderate speeds at constant brake pressure, to satisfy the strong need for global standardization of squeal noise dynamometer tests. This procedure is applicable to high-frequency squeal noise occurrences for on-road passenger cars and light trucks [24].

Based on the SAE J2521 test procedure, the dynamometer test of the brake assembly was performed by LINK Model $3900 \mathrm{NVH}$ test dynamometer (Figure 3), and the noise signal during the test was recorded by a microphone. For the purposes of this test procedure, squeal noise is defined as peak noise levels equal to or above $70 \mathrm{~dB}(\mathrm{~A})$ between $2 \mathrm{kHz}$ and $16 \mathrm{kHz}$ for brakes not using a full suspension corner [24]. The relationships between the absolute noise occurrence and the average brake pressure, initial brake speed, and initial rotor temperature were determined, as shown in Figures 4-6, respectively. The results of the dynamometer test showed significant differences in the absolute noise occurrence under different working conditions. This proved that the working parameters can have significant effects on the generation of brake noise.

The brake noise may be affected by the working parameters directly or indirectly. Direct effects are caused by changes in the working parameters themselves. Indirect effects are caused by performance variations of parts in the brake assembly from changes in the working parameters. The FEM was used to examine both the direct and indirect effects to investigate the influence of working parameters on the brake noise.

3.2. Direct Influence of Working Parameters on Brake Noise. Some working parameters of the braking system could affect braking noise directly. Based on the major brake pressure and initial brake speed parameters in the SAE J2521 test procedure, nine parameter combinations were selected with a brake pressure of $1.0,2.0$, or $3.0 \mathrm{MPa}$ and an initial brake speed of 3,5 , or $10 \mathrm{~km} / \mathrm{h}$. The finite element model was modified depending on the values of the above parameters and recalculated. To analyze the instability of each model, the tendency of instability (TOI) was introduced as a stability evaluation index for the brake system [25]:

$$
\mathrm{TOI}=\sum_{i}\left(\frac{\sigma_{i}}{\omega_{i}} \cdot 1000\right), \quad \sigma_{i}>0 .
$$

The negative ratio of $\sigma_{i}$ and $\omega_{i}$ is the damping ratio of the corresponding mode. Therefore, TOI is positively correlated with system instability according to equation (6). Table 4 presents the TOI values of different working conditions.

Table 4 indicates that the TOI is not significantly changed by direct modification of the brake pressure or initial brake speed of the finite element model. However, the dynamometer test results in Figures 4 and 5 indicate that the occurrence of brake noise was clearly affected by variations in the brake pressure and initial brake speed. Therefore, direct changes to the working parameters are not the major cause of changes in the brake noise.

3.3. Indirect Influence of Working Parameters on the Brake Noise. In the present study, nonasbestos organic (NAO) material was selected as the friction material of the brake lining. The friction coefficient of an NAO material is affected by variations in the brake speed, brake pressure, and temperature. Meanwhile, the elastic modulus of an NAO material also changes with the temperature. Therefore, the indirect influence of working parameters on the brake noise is mainly from variations in the performance parameters of the friction material and can be examined by modifying the friction coefficient and elastic modulus of the brake material in the finite element model. For the performance parameters of the brake material, a friction coefficient range of $0.3-0.5$ and an elastic modulus range of 550-950 MPa were chosen. Then, 81 parameter combinations were considered to modify the finite element model. Figure 7 shows the relationship between TOI and the performance parameters.

TOI showed significant changes when the friction coefficient or elastic modulus of the friction material was changed. The indirect influence of variations in the working conditions on the brake noise was found to be much more significant than the direct influence. This may be an important factor that affects the brake noise. In addition, the variation in TOI with changes to the friction coefficient and elastic modulus showed significant nonlinear and nonmonotonic properties. This reflects the interaction between the above parameters. Therefore, in order to reduce the occurrence of brake noise under general working conditions, the indirect influence of the working parameters should be considered in the design of a brake system.

\section{Optimization of Brake Lining Parameters Based on Monte Carlo Sampling and PSO}

4.1. Parameter Selection and Structure Description of the Optimization Method. In the present study, the friction coefficient and elastic modulus were chosen as the material optimization parameters. The chamfer dimension (i.e., 
Table 3: Noisy modes in the finite element analysis.

\begin{tabular}{lccc}
\hline Modal order & Frequency $(\mathrm{Hz})$ & Eigenvalue (real part) & Damping ratio $\left(10^{-2}\right)$ \\
\hline 64 & 3880.3 & 192.20 & -0.7883 \\
99 & 7809.3 & 307.12 & -0.6259 \\
104 & 8201.8 & 698.59 & -1.3555 \\
110 & 8837.3 & 534.63 & -0.9628 \\
134 & 10885.0 & 609.76 & -0.8915 \\
\hline
\end{tabular}

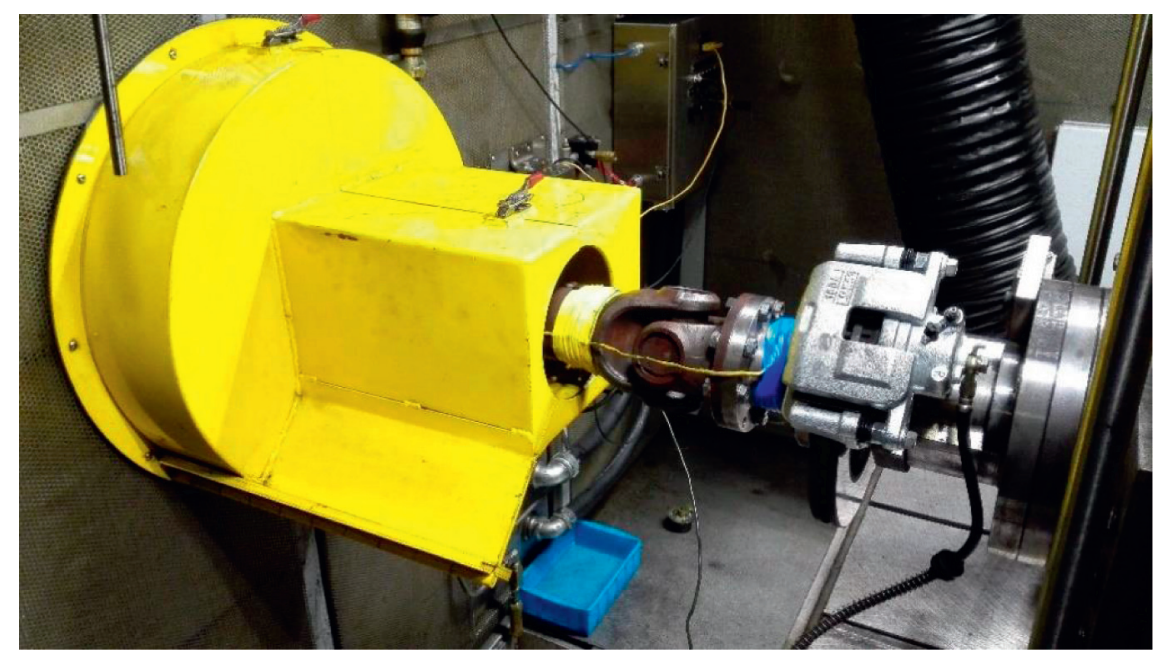

FIGURE 3: Brake assembly and dynamometer.

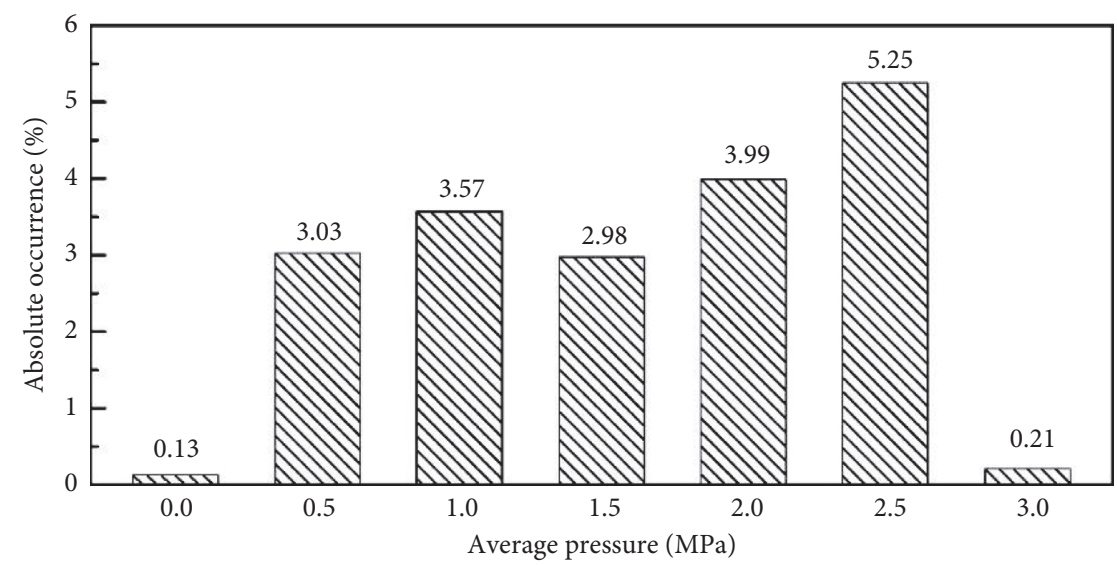

Figure 4: Absolute noise occurrence for different average pressures.

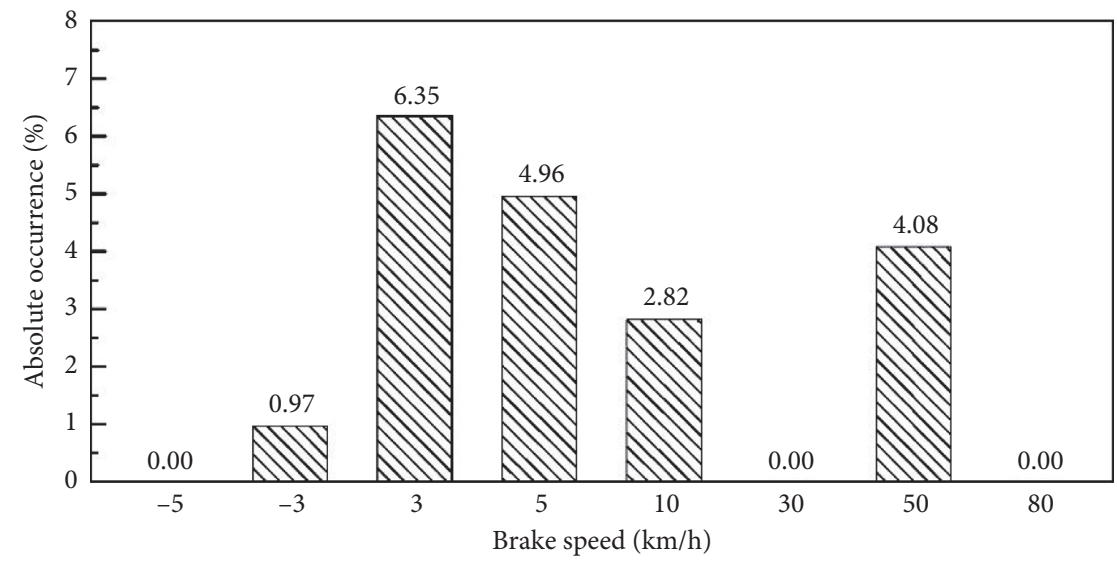

FIGURE 5: Absolute noise occurrence for different brake speeds. 


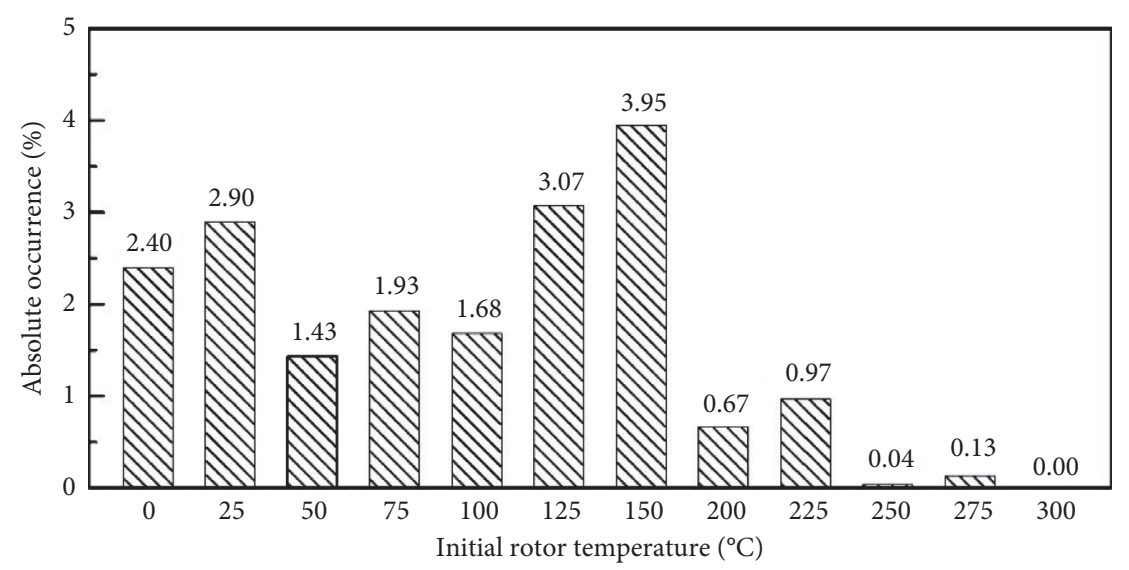

Figure 6: Absolute noise occurrence for different initial rotor temperatures.

TABLE 4: Direct effects of working conditions on TOI.

\begin{tabular}{lccc}
\hline No. & Brake pressure $(\mathrm{MPa})$ & Initial speed $(\mathrm{km} / \mathrm{h})$ & TOI \\
\hline 1 & 1.0 & 3.0 & 53.51 \\
2 & 1.0 & 5.0 & 53.64 \\
3 & 1.0 & 10.0 & 50.47 \\
4 & 2.0 & 3.0 & 56.65 \\
5 & 2.0 & 5.0 & 56.20 \\
6 & 2.0 & 10.0 & 55.60 \\
7 & 3.0 & 3.0 & 58.00 \\
8 & 3.0 & 5.0 & 57.32 \\
9 & 3.0 & 10.0 & 56.35 \\
\hline
\end{tabular}

width of the chamfer bottom edge) was also used for the structural optimization parameter (Figure 8). The optimization ranges of the friction coefficient $\mu$, elastic modulus $E$, and chamfer dimension $S$ were set to $0.37-0.42$, $550-750 \mathrm{MPa}$, and $0-21 \mathrm{~mm}$, respectively.

The response surface method was used to establish the functional relationship between the optimization parameters and TOI [26]. Because changing the parameters induced obvious nonmonotonic and nonlinear characteristics in TOI, as shown in Figure 7, the response surface was divided into blocks to improve the fitting precision. The Monte Carlo method was used to randomly sample the search space to reflect the influence of random working conditions on the brake noise. Finally, PSO was used to obtain the optimal parameter combination in the search space.

4.2. Establishment of Blocked Response Surfaces. The Box-Behnken design (BBD) method was used to build the response surface [26]. To consider the nonmonotonic and nonlinear characteristics shown in Figure 7 , the response surface was divided as follows: the range of each parameter was divided into three sections of the same size, and the whole response surface was divided into 27 subresponse surfaces. Figure 9 shows the corresponding experimental points for each parameter.

Based on the corresponding combinations of optimization parameters presented in Figure 9, the finite element model was modified and submitted for analysis. Design Expert 10 software was used to build the subresponse surfaces [27]. The input variables included the elastic modulus, friction coefficient, and chamfer dimension, while the response variable was TOI. Analysis of variance was performed to validate the significance of each subresponse surface, and F-value and $P$-value were used to indicate the statistical significance and hypothesis test result of the functions [26]. The results showed that all functions satisfied the condition of significant $\left(F>F_{0.05}=3.86\right)$. Over $90 \%$ of the response surfaces satisfied the condition of very significant $\left(F>F_{0.01}=6.99\right)$. Moreover, the $P$-value of each function was less than 0.01 . The results showed that the above subresponse surfaces had good statistical significance. To achieve the requirements of parameter optimization, all 27 subresponse surfaces were patched into a whole response surface through the construction of a piecewise function.

4.3. Monte Carlo Sampling Based on a Probability Density Function. Establishing a perfect mathematical model between the working parameters and brake noise is difficult because of the complex composition and random regularity. Because of the randomness of the working parameters, the Monte Carlo sampling method was introduced [28]. Random sampling was performed on the response surface according to the probability density function of the material parameters, and the probability density function was obtained from the results of the dynamometer test. This approach allows the indirect effects of the working parameters on the brake noise to be considered and solves the problem of discontinuity between the subresponse surfaces.

In the present study, a brake assembly was equipped with a pair of brake linings using an NAO friction material with a nominal friction coefficient of $\mu_{n}=0.40$. Based on SAE J2521, a dynamometer test was carried out. Figure 10 shows the measured average friction coefficient. The probability distribution of the friction coefficient showed strong features of a normal distribution.

The average friction coefficient of each effective brake was recorded and fitted to the function of a normal distribution. The fitting results showed that the friction coefficient of the NAO material under various working conditions was subjected to the normal distribution $N$ 


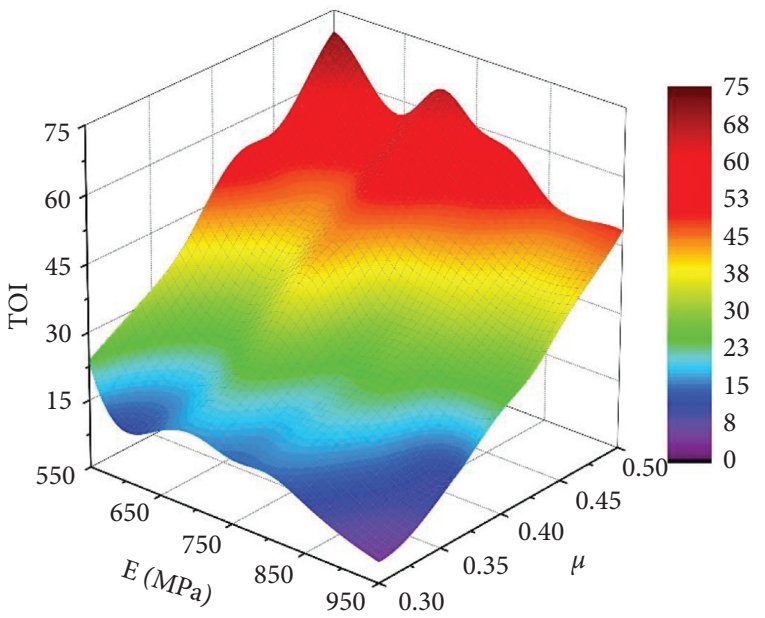

Figure 7: Indirect effects of working conditions on TOI.

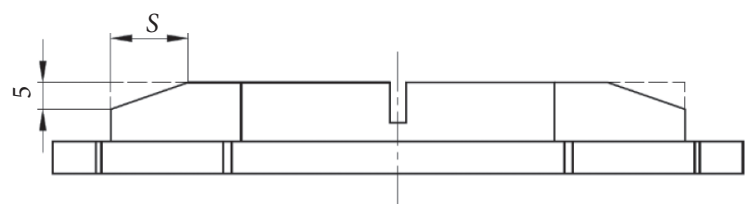

FIGURE 8: Chamfer optimization parameter for the brake lining.

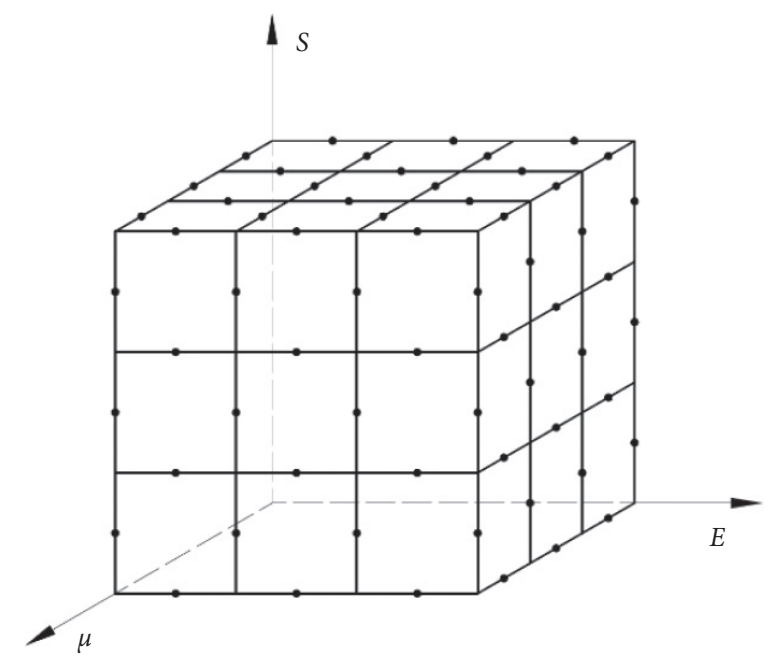

FIGURE 9: Block of input parameters for the response surface.

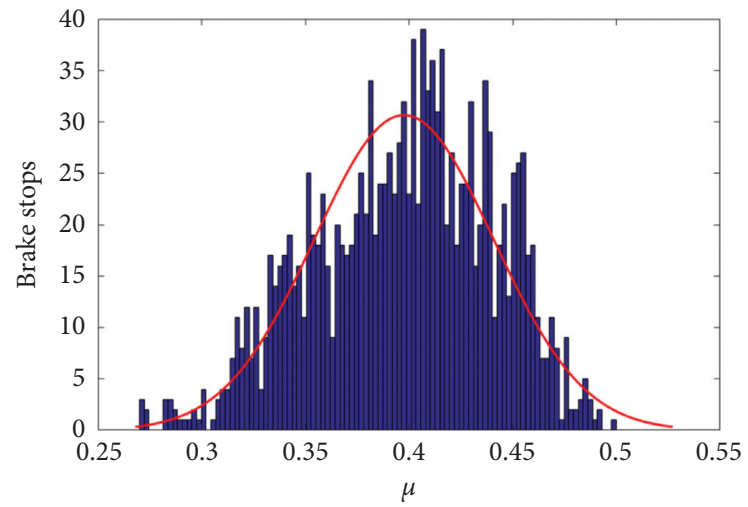

FIgURE 10: Probability distribution of the friction coefficient from the SAE J2521 test. 
TABLE 5: Test results for the compressive strain of the brake lining.

\begin{tabular}{|c|c|c|c|c|}
\hline \multirow{2}{*}{ Recorded pressure ( $\mathrm{MPa})$} & \multicolumn{2}{|c|}{ Thickness variation $(\mu \mathrm{m})$} & \multicolumn{2}{|c|}{ Compressive strain $\left(10^{-3}\right)$} \\
\hline & Room temp & High temp & Room temp & High temp \\
\hline 2.0 & 14 & 21 & 0.78 & 1.18 \\
\hline 4.0 & 30 & 43 & 1.68 & 2.41 \\
\hline 10.0 & 71 & 90 & 3.97 & 5.04 \\
\hline 16.0 & 110 & 132 & 6.16 & 7.39 \\
\hline
\end{tabular}

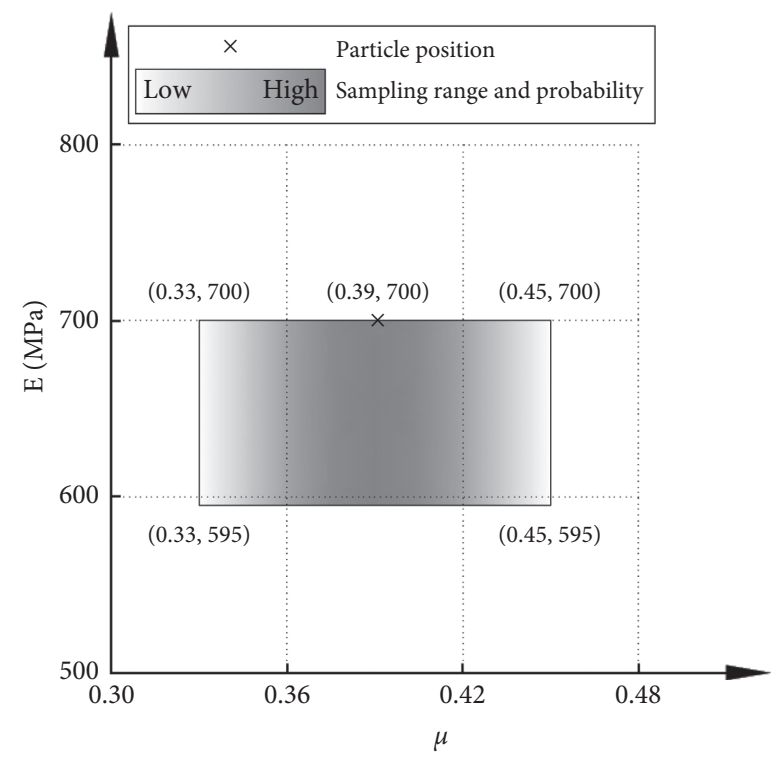

Figure 11: Sampling of the elastic modulus and friction coefficient.

$\left(0.3976,0.0432^{2}\right)$. The probability density function is expressed in Eq. (8). A range of $\mu \pm 0.06$ was selected as the sampling interval, which corresponded to a confidence level of $83.6 \% .1$

$$
f(x)=\frac{1}{0.0432 \cdot \sqrt{2 \pi}} \exp \left(-\frac{(x-0.3976)^{2}}{2 \cdot 0.0432^{2}}\right) .
$$

The temperature was found to have a major influence among the working conditions on the elastic modulus of the friction material. The elastic modulus decreased with increasing temperature. The average thickness variation and compressive strain of the brake linings at room temperature and high temperature were measured according to ISO6310: 2009 (Table 5) [29]. The test results were used to modify the elastic modulus of the friction material under different temperature conditions.

The elastic modulus of the friction material at different temperatures was calculated as follows: $709 \mathrm{MPa}$ at room temperature $\left(25^{\circ} \mathrm{C}\right)$ and $591 \mathrm{MPa}$ at high temperature $\left(400^{\circ} \mathrm{C}\right)$. Because the variation in the elastic modulus showed only a small amplitude within the experimental range, a linear function was established to represent the relationship between the temperature $t$ and elastic modulus $E$ :

$$
E(t)=709-0.3147 \cdot(t-25), \quad 25 \leq t \leq 400 .
$$

The maximum initial brake temperature as per SAE J2521 was $300^{\circ} \mathrm{C}$ except for the after-fade section. The corresponding elastic modulus was $622 \mathrm{MPa}$, which is $87.7 \%$ of the value at room temperature. Because the occurrence frequency of different initial temperatures is similar according to SAE J2521, a uniform distribution was used to sample the elastic modulus of the friction material. Based on the nominal elastic modulus $E$, the elastic modulus of friction material for computing was sampled within the range of $0.85 E-1.0 E$. And the friction coefficient for computing was sampled within the range of $\mu \pm$ 0.06 , corresponding to the normal distribution shown as $N(\mu$, 0.04322). Figure 11 shows an example of the sampling range and probability distributions of the friction coefficient and elastic modulus of the friction material: if the nominal friction coefficient is 0.39 and the nominal elastic modulus is $700 \mathrm{MPa}$, the sampling range would be a rectangular area in the coordinate system, and the color depth in the figure indicates the probability of sampling.

4.4. PSO and Validation of the Results. PSO was proposed in 1995, which comes from the simulation of simplified social model [30]. A program based on PSO algorithm was carried out by MATLAB, and it was used to find the optimal value on the response surface. The population size and number of iterations were set to 40 and 2000, respectively. Each particle was sampled 1000 times in the search space, and the average value of the samples was calculated as the fitness of algorithm. In order to avoid the effect of random sampling on the optimization results, the algorithm was executed repeatedly and independently 


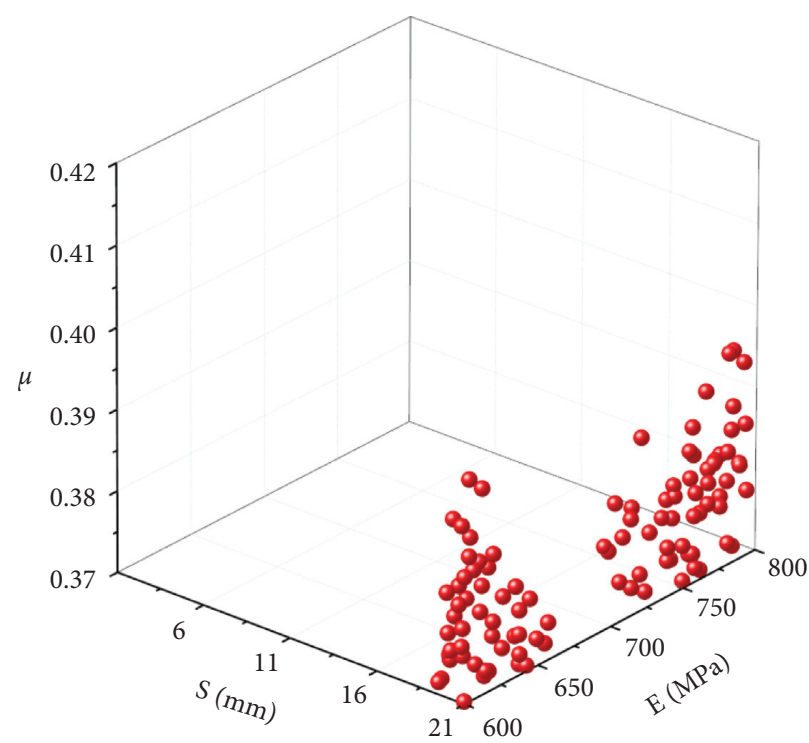

FIGURE 12: Distribution of parameter optimization results.

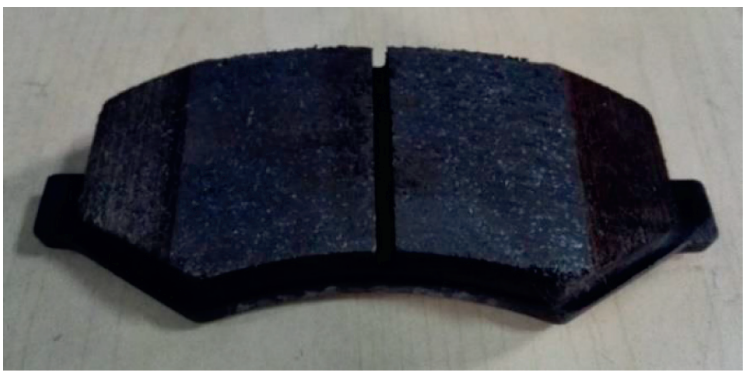

FIGURE 13: Brake lining after optimization.

TABLE 6: Noisy stops with the original and optimized schemes.

\begin{tabular}{lccc}
\hline Frequency range & Threshold & Original & Noisy stops \\
& & 456 & Optimized \\
$2-16 \mathrm{kHz}$ & $\geq 70 \mathrm{~dB}$ & 329 & 21 \\
& $\geq 80 \mathrm{~dB}$ & 45 & 11 \\
$2-4 \mathrm{kHz}$ & $\geq 70 \mathrm{~dB}$ & 34 & 0 \\
& $\geq 80 \mathrm{~dB}$ & 32 & 0 \\
$4-6 \mathrm{kHz}$ & $\geq 70 \mathrm{~dB}$ & 25 & 0 \\
& $\geq 80 \mathrm{~dB}$ & 147 & 127 \\
$6-10 \mathrm{kHz}$ & $\geq 70 \mathrm{~dB}$ & 20 & 11 \\
& $\geq 80 \mathrm{~dB}$ & 232 & 0 \\
$10-14 \mathrm{kHz}$ & $\geq 70 \mathrm{~dB}$ & 143 & 0 \\
$14-16 \mathrm{kHz}$ & $\geq 80 \mathrm{~dB}$ & 0 & 0 \\
& $\geq 70 \mathrm{~dB}$ & & 0 \\
\hline
\end{tabular}

according to Bernoulli's experimental method [31]. Optimized points with TOI values of less than 8.0 were selected as good results. The algorithm was performed repeatedly until 100 good points were obtained. Figure 12 shows the 100 combinations of optimal parameters with low TOI values.

The optimal friction coefficient was concentrated in the range of $0.37-0.39$, while the optimal chamfer dimension was concentrated in the range of $19-21 \mathrm{~mm}$. However, particles showed good fitness when the elastic modulus was within either
600-650 MPa or 750-800 MPa. An NAO brake material with a smaller elastic modulus is less wear-resistant; because part of the friction material is removed when the chamfers are set, this would reduce the service life of the brake linings. Therefore, a friction material with an elastic modulus of $780 \mathrm{MPa}$ and friction coefficient of 0.38 was selected, and chamfers with a bottom width of $20.5 \mathrm{~mm}$ were set on both sides of the brake linings. Figure 13 shows the produced samples with the optimized brake lining. 


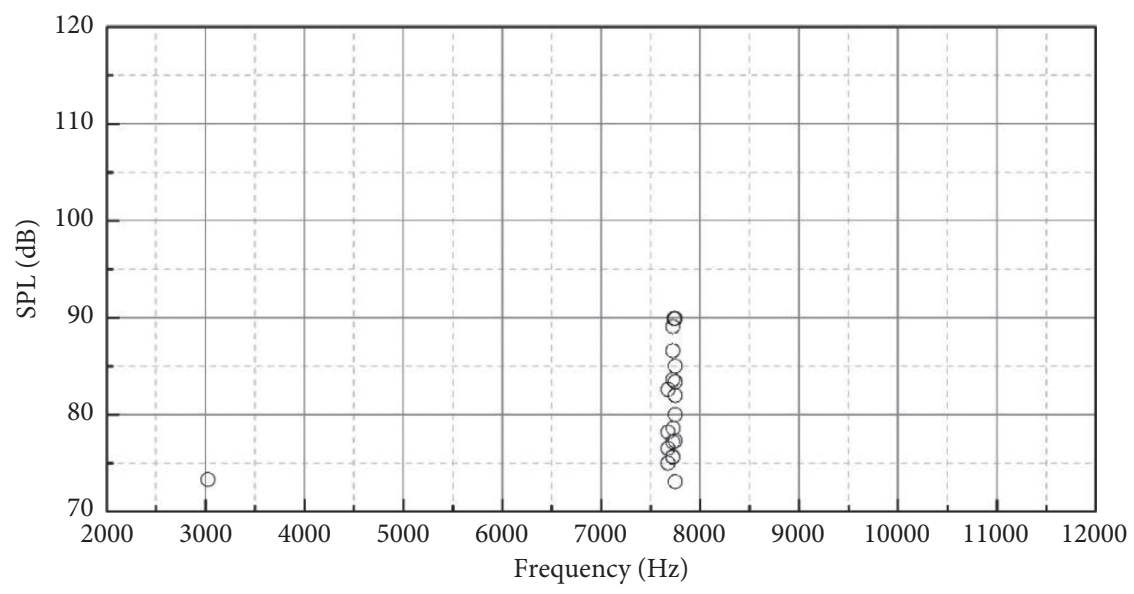

Figure 14: Noise distribution during the dynamometer test after optimization.

A dynamometer test based on SAE J2521 was carried on a brake assembly equipped with the optimized brake linings shown in Figure 13. Table 6 presents the occurrence of brake noise before and after optimization, and Figure 14 shows the brake noise distribution. Compared with the original scheme with 456 noisy stops, the optimized scheme had only 21 noisy stops. The proportion of the occurrence of brake noise to the total number of brakes decreased from $19.2 \%$ to $1.4 \%$, which represents a significant decrease in the probability of occurrence.

The brake noise acceptability of the optimized scheme was evaluated based on SAE J2521. The overall noise index was AA, and the noise index of Schedule A (standard) and Schedule C (after fade) reached the highest level of AAA. Compared with the noise index B before optimization, the optimization scheme significantly suppressed the brake noise. Therefore, the optimized brake lining design scheme can effectively reduce noise during the braking process, and the optimization method of reducing brake noise based on Monte Carlo sampling and PSO was found to be effective.

\section{Conclusion}

A dynamometer test was used to study the influence of working parameters on the brake noise, and the FEM was used to study the direct and indirect effects of the working parameters. An optimization method of reducing the brake noise based on Monte Carlo sampling and PSO was used to optimize the brake linings. The results of the study are summarized as follows:

(1) During the braking process, working parameters including the brake pressure, brake speed, and temperature have a significant impact on the occurrence of brake noise.

(2) Working parameters mainly have an indirect effect on the brake noise by changing the properties of the components in the brake assembly. Parameters affected by the working conditions mainly include the elastic modulus and friction coefficient of the friction material.
(3) The effect of random working conditions on the material parameters during the braking process can be simulated with Monte Carlo sampling. An optimization method for reducing brake noise based on Monte Carlo sampling and PSO was presented that considers the influence of working conditions. The results of a dynamometer test showed the effectiveness of the optimization method.

\section{Data Availability}

The noise data used to support the findings of this study are included within the article.

\section{Conflicts of Interest}

The authors declare that they have no conflicts of interest.

\section{References}

[1] D. P. Wang, J. S. Cao, and W. Z. Liu, "Noise analysis of disc brake for automobile," Applied Mechanics and Materials, vol. 483, pp. 271-274, 2014.

[2] M. S. Qatu, "Recent research on vehicle noise and vibration," International Journal of Vehicle Noise and Vibration, vol. 8, no. 4, pp. 289-301, 2012.

[3] L. J. Zhang, K. Diao, and D. J. Meng, "Friction-induced vibration and noise research: the status quo and its prospect," Journal of Tongji University (Natural Science), vol. 41, no. 5, pp. 765-772, 2012.

[4] G. D. Liles, "Analysis of disc brake squeal using finite element methods," SAE Technical Paper. No. 891150, SAE International, Warrendale, PA, USA, 1989.

[5] M. Dezi, P. Forte, and F. Frendo, "Motorcycle brake squeal: experimental and numerical investigation on a case study," Meccanica, vol. 49, no. 4, pp. 1011-1021, 2014.

[6] M. S. Xie, G. R. Zhang, J. H. Li, and R. Fritsch, "Brake pad taper wear on brake moan noise," International Journal of Automotive Technology, vol. 15, no. 4, pp. 565-571, 2014.

[7] S. Oberst and J. C. S. Lai, "Statistical analysis of brake squeal noise," Journal of Sound and Vibration, vol. 330, no. 12, pp. 2978-2994, 2011. 
[8] M. T. Junior, S. N. Gerges, and R. Jordan, “Analysis of brake squeal noise using the finite element method: a parametric study," Applied Acoustics, vol. 69, no. 2, pp. 147-162, 2008.

[9] M. Esgandari, R. Taulbut, and O. Olatunbosun, "Effect of damping in complex eigenvalue analysis of brake noise to control over-prediction of instabilities: an experimental study," SAE Technical Paper No. 2013-01-2034, SAE International, Warrendale, PA, USA, 2013.

[10] P. Liu, H. Zheng, C. Cai et al., "Analysis of disc brake squeal using the complex eigenvalue method," Applied Acoustics, vol. 68, no. 6, pp. 603-615, 2007.

[11] C. Vayssière, L. Baillet, V. Linck, and Y. Berthier, "Influence of Contact Geometry and Third Body on Squeal Initiation: Experimental and Numerical Studies," in Proceedings of the World Tribology Congress III, ASME, Washington, DC, USA, September 2005.

[12] P. Stegmann, S. Kruse, and K. Augsburg, "Robustness of Disc Brake Systems Regarding Squeal," in Proceedings of the 33th International Modal Analysis Conference, SEM, Orlando, FL, USA, February 2015.

[13] O. Fazio, S. Nacivet, and J. J. Sinou, "Reduction strategy for a brake system with local frictional non-linearities-application for the prediction of unstable vibration modes," Applied Acoustics, vol. 91, pp. 12-24, 2015.

[14] T. Tison, A. Heussaff, F. Massa, I. Turpin, and R. F. Nunes, "Improvement in the predictivity of squeal simulations: uncertainty and robustness," Journal of Sound and Vibration, vol. 333, no. 15, pp. 3394-3412, 2014.

[15] K. Soobbarayen, J.-J. Sinou, and S. Besset, "Numerical study of friction-induced instability and acoustic radiation - effect of ramp loading on the squeal propensity for a simplified brake model," Journal of Sound and Vibration, vol. 333, no. 21, pp. 5475-5493, 2014.

[16] W. K. Lee, M. W. Shin, S. H. Kim, H. Jang, and M. H. Cho, "The influence of humidity on the sliding friction of brake friction material," Wear, vol. 302, no. 1-2, pp. 1397-1403, 2013.

[17] A. Renault, F. Massa, B. Lallemand, and T. Tison, "Experimental investigations for uncertainty quantification in brake squeal analysis," Journal of Sound and Vibration, vol. 367, pp. 37-55, 2016.

[18] H. Lü and D. Yu, "Stability optimization of a disc brake system with hybrid uncertainties for squeal reduction," Shock and Vibration, vol. 2016, p. 2016.

[19] Z. Zhang, S. Oberst, and J. Lai, "Instability analysis of friction oscillators with uncertainty in the friction law distribution," Proceedings of the Institution of Mechanical Engineers, Part C: Journal of Mechanical Engineering Science, vol. 230, no. 6, pp. 948-958, 2015.

[20] H. Lü and D. Yu, "Brake squeal reduction of vehicle disc brake system with interval parameters by uncertain optimization," Journal of Sound and Vibration, vol. 333, no. 26, pp. 7313-7325, 2014.

[21] H. Lü and D. Yu, "Uncertainty optimization of vehicle brakes based on interval analysis," Automotive Engineering, vol. 37, no. 7, pp. pp807-812, 2015.

[22] Altair Engineering Inc., HyperWorks 14.0 Desktop User Guides, Altair Engineering Inc., Irvine, CA, USA, 2015.

[23] Dassault Systemes Simulia Corp., Abaqus Analysis User's Manual Version 6.13, Dassault Systemes Simulia Corp., Providence, RI, USA, 2013.

[24] SAE International, Disc and Drum Brake Dynamometer Squeal Noise Test Procedure, SAE International, Warrendale, PA, USA, 2013.
[25] D. H. Guan and D. Y. Jiang, "A study on disc brake squeal using finite element methods," SAE Technical Paper. No. 980597, SAE International, Warrendale, PA, USA, 1998.

[26] L. Eriksson, E. Johansson, N. Kettaneh-Wold, C. Wikström, and S. Wold, "Design of experiments," Principles and Applications, Learn Ways AB, Stockholm, Sweden, 2000.

[27] Stat-Ease Inc., Design-Expert $10 \mathrm{Help} \mathrm{Manual,} \mathrm{Stat-Ease} \mathrm{Inc.,}$ Minneapolis, MN, USA, 2015.

[28] R. Y. Rubinstein and D. P. Kroese, Simulation and the Monte Carlo Method, Vol. 10, John Wiley \& Sons, Hoboken, NJ, USA, 2016.

[29] International Organization for Standardization, Road Vehicles-Brake Linings-Compressive Strain Test Methods, International Organization for Standardization, Geneve, Switzerland, 2009.

[30] J. Kennedy and E. Russell, "Particle swarm optimization," in Proceedings of the ICNN'95-International Conference on Neural Networks, vol. 4, IEEE, Perth, Australia, NovemberDecember 1995.

[31] M. H. DeGroot and M. J. Schervish, Probability and Statistics, Vol. 2, Addison-Wesley, Reading, MA, USA, 1986. 